\title{
A Shift from Teacher Centered to Learner Centered Approach
}

\author{
http://dx.doi.org/10.3991/ijep.v4i3.3395 \\ Jeanne Schreurs ${ }^{1}$, Roza Dumbraveanu ${ }^{2}$ \\ ${ }^{1}$ Hasselt University, Hasselt, Belgium \\ ${ }^{2}$ State Pedagogical University, Chisinau, Moldova
}

\begin{abstract}
In the framework of the project Western Eastern Teachers' Education Network (WETEN) funded by the Tempus program the network of university teachers were established to share expertise on effective teaching and learning in universities. This network for pedagogical innovation in higher education brought together the experts from EU to share good practice and new teaching methods with academic staff from two eastern countries, Moldova and Ukraine. The learner centered concept was analyzed and guidelines for creating learner centered courses were developed and piloted. The concepts and some experiences in course design were also implemented by trained teachers in the developed courses within the WETEN project.
\end{abstract}

Index Terms-Continuous professional development, teacher training, learner centered approach.

\section{INTRODUCTION}

$\mathrm{T}$ Professional development of the academic staff has an important contribution to make in the realization of the Bologna objectives. Bologna changes have as consequences the increasing demands made on academic staff to contribute to life-long learning activities and to change the focus from teacher training approach to student centered learning [1], [2].

This change in teaching approaches implies sustaining reform of the initial and of the continuous training of teachers and trainers to prepare them for their new responsibilities [3]. The authors intend to present some results of the Tempus Project WETEN and some contributions used as best practices for the project developments [4]. The project has been formed as a network of European university teachers that should promote collaborative work and create a community of practice particularly focused on engaging academia in the enhancement of teaching and learning. The best practices refer to:

- teaching/learning/assessment (TLA) approaches;

- institutional implementation of these models;

- information and communication technology (ICT) and enhancement of TLA;

- training of Higher Education (HE) teachers;

- quality assurance in course design.

The main challenge is to change the university teachers' mentality regarding the course design. Teachers and teaching teams must be able:

- to identify and to describe the learning outcomes of the curriculum;
- to construct and to implement the curriculum map of alignment;

- to define the learning outcomes per each program course;

- to identify and to implement the appropriate teaching, learning and assessment techniques, t. e. to guarantee the fulfillment of the constructive alignment;

- to provide evidence of quality assurance of the approaches used.

The competence of teachers to reflect upon their practice and to employ appropriate teaching strategies and methods, therefore, is a crucial one which any Higher Education Institution should seek to promote. The WETEN network was particularly concerned in reflecting, discussing, sharing experiences and enhancing the quality of $\mathrm{HE}$ teaching and learning. This paper is devoted especially to: a) student-centered educational approach; b) ICT strategies to improve the learning experience and to focus on learners' autonomous work; and c) training of HE teachers to improve their pedagogical competences.

\section{COURSE DESIGN IN THE LEARNER CENTERED APPROACH}

\section{A. General description}

The traditional way of designing courses called teacher centered approach is to start from the content of the course. Teachers decided on the content that they intended to teach, planned how to teach this content and then assessed the content. This approach is based on the teacher's input and on assessment in terms of how well the students learned/reproduced the material taught. Course descriptions referred mainly to the content of the course that would be covered in lectures.

International trends in education show a shift from the traditional teacher centered approach to a student centered approach [5]. This model focuses on what the students are expected to be able to do at the end of the course. This approach is commonly referred to as an outcome-based approach. Statements called learning outcomes are used to express what it is expected that students should be able to do at the end of the learning period [20]. Learning outcomes are clear statements of what the student is expected to achieve and how the student is expected to demonstrate this achievement as a result of engaging in the learning process.

Learning outcomes are one of the most important sections of the course and program outline - the essence of the course and of the student centered approach. By read- 
ing the listed learning outcomes, an employer or professional in the field should be able to identify what knowledge, skills, and attitudes the students will be able to offer them after taking the course.

Learning outcomes are the first component in the student centered approach course design. It must be complemented by the constructive alignment [6], [7]. Constructive alignment means that the learner constructs his own learning through relevant learning activities. The teacher's responsibility is to create a learning environment that supports the learning activities appropriate to achieving the intended learning outcomes. The essence is that all components in the teaching system - the intended learning outcomes, the used teaching methods, the resources to support learning, the learning activities and the assessment tasks and criteria for evaluating learning - are aligned to each other and facilitate the achievement of the intended learning outcomes.

Constructive alignment has two facets. The constructive facet refers to the students: they construct meaning and understanding through relevant learning activities. The teacher's main task is to engage students in learning activities that will result in achieving learning outcomes. The alignment facet refers to the teacher, which should design the learning activities appropriate for achieving the intended learning outcomes. The main point is that the components in the teaching system, especially the teaching methods used and the assessment tasks are aligned with the learning activities assumed to achieve the intended outcomes. This approach can be abbreviated as LOLALA, meaning the alignment of: learning outcomes - learning activities - learning assessment.

In this way the shift occurs in the education approach by changing the focus from the teacher to the learners. The learners are the active makers of knowledge and they are even co-responsible for knowledge creation, being presented with real life problems in collaborative and social environment in which they apply their skills and experience to solve the problems and even to construct the knowledge. The learning environment is no more limited to the classroom, but it includes the classroom, the workplace, home, etc. and is enriched by ICT and facilitated by LMS (Learning Management System) and social networks. In learner-centered approach, the learning process is also preparing the learner for the lifelong learning [8], [9].

\section{B. Constructivism}

In Reference [7], the following definition about constructivism can be found:

"Constructivism learning theory is defined as active construction of new knowledge, based on learner's prior experience”.

Following Reference [10], the concept of constructivist learning can be structured in four core features: knowledge construction, cooperative learning, selfregulated learning and using real world problems. Knowledge construction is the core element of the constructivism theory, in which learners interpret new information using knowledge and experience they already have. Cooperative learning is essential for knowledge construction and sharing, in which learners, teachers, and external experts of the study-domain contribute to the construction of knowledge through social interactions.
Self-regulation which includes setting learning objectives, self-observation, self-assessment, and self-reinforcement, is believed that it has a great influence on learning outcomes and learners' performance. Finally, in constructivism learning, learning process has to include real life situations. Problem solving develops critical thinking skills and prepares the learners for professional work environment [11]. Project based learning is a good example of constructivist learning. In project based learning learners' interaction and cooperation will increase and will result in new knowledge construction and in sharing it with other learners.

Constructivism theory is the learning concept in which learners construct their own knowledge through their personal experience. Learners are encouraged to engage effectively in the organized learning activities. They will explore, discuss, negotiate, collaborate, cooperate, investigate, and solve real life problems in social learning environment [12]. They will interact with the environment (physical and social world), to develop social and interpersonal skills and knowledge.

\section{Constructivist learning activities}

Learner centered learning means that the curriculum and the courses take into account some predefined competences. So learner centered means also competence directed learning.

Murphy [13] developed a list of 18 constructivist learning characteristics. The list is now extended, including characteristics linked with competency directed learnercentered learning, social constructivism and more specific the aspects of collaborative construction of knowledge. This new constructivist model is structured in five main categories. The learning characteristics are: an active and guided learning process; deep conceptualized learning with multiple perspectives; construction of new learning content; collaborative learning and orientation of learning on the future.

Constructivist learning activities must include as much as possible constructivist learning characteristics. Following are some candidate learning activities.

- Reading about a selected topic on the Internet and discuss it with other learners and with the teacher.

- Searching for and presenting a real-world example of a selected topic.

- Contact with an external domain expert talking about a selected topic, reporting about it and exchanging that knowledge with other learners of the team.

- Search for additional knowledge including scientific articles covering the topic.

- Teamwork and preparing/writing a team paper reporting about the project results.

- Solving a real life problem by discussing the problem, searching for the required knowledge and methods, discussing with experts about it and reporting about the solution.

- Presentation of learner reaction in an article based on his/her previous knowledge.

- Reporting via a 400 - 500-word essay by each team of learners, explaining their interpretation and reaction about their colleagues' postings. 
- Elaborating a wiki (structured by the teacher) about a selected topic, as a team activity.

- Participating in a discussion session (real or virtual) and sharing knowledge and vision.

- Group preparation of a report/task about a selected topic, sharing the reports with other learners and assessing the input of all of them.

\section{TEACHERS IN THE STUDENT CENTERES PROCESS}

\section{A. Teachers designing a Constructivism Based Learning Process}

Teacher's role is essential and important in the learning process. A teacher is a facilitator and guide, and not a director or a dictator. He will facilitate learning activities, will try to understand how learners interpret knowledge, will guide and help them to refine their understanding and interpretations, will correct any misconception that can arises between learners at an early stage, and will improve the learned knowledge quality [14].

The constructivist teachers' role is to create a context where the learner is motivated to learn; which includes providing content and resources and organizing constructivist learning activities. Teachers will use methods from both theories, the cognitive and the social constructivism, and will develop individual learning methods such as discovery learning, and social interactive activities to develop peer collaboration [15]. They will be able to formulate relevant problems and questions and will link the resources and questions to the learners' prior knowledge. It is recommended to organize debates in the classroom about an interesting phenomenon/process and to provide means for learners to experience real world or meaningful practices. Because learners learn from examples, they will have afterwards experience in a relevant practice. In writing essays they are reporting about their own selected topics of their reading assignments [16].

Teamwork and collaborative learning are main elements of the learning process. Project based and problem based approach are essential in higher level learning.

In order to increase student motivation, a competition between groups can be introduced. Competition Based Learning [17] is a methodology where the use of a friendly final competition objective provides strong motivation for students and maintains a certain healthy level of stress during the learning process. Healthy means that the end score may not be influenced too strong by the outcome of the competition.

The assessment has to be more integrated in the learning process and learners will take also responsibility in it.

Constructivism based learning process has to be designed by the teacher. Our design model [7] consists of learning design elements and learning assessment elements. Learning design elements consist of fundamental design elements and collaborative design elements as illustrated in Fig. 1. In this design model fundamental design elements were included and structured in 3 categories: first - implementation of problem solving and higher-order thinking; second - the activity of searching for additional knowledge and third - the delivery of relevant context of learning, by creating a link with the external domain expertise.

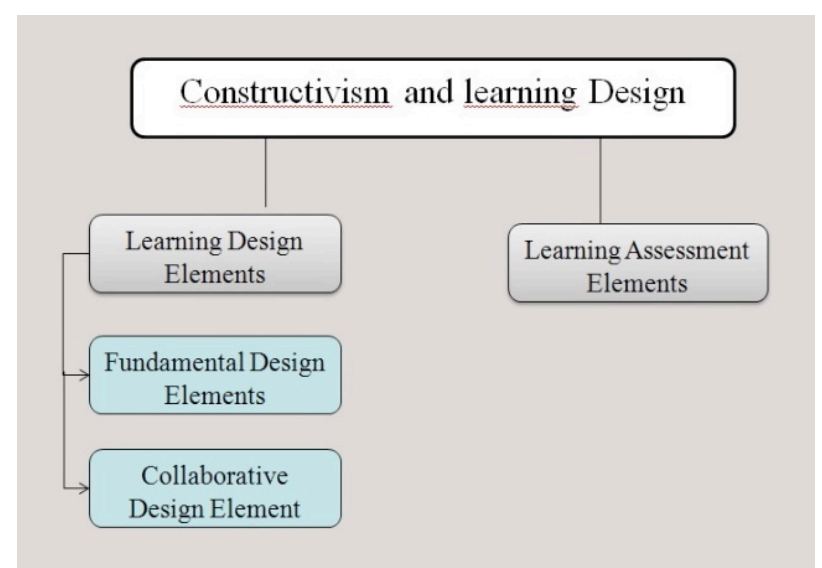

Figure 1. Constructivism Based Learning Process Design Model [7].

The collaborative design elements are essential for collaboration and constructing new knowledge. Here the advantages of learning in a team of learners are set forward. The learning assessment elements include: selfassessment, team assessment, and teacher assessment. Assessment is an essential part of the learning process and has to be integrated within a project or in a task rather than being a separate activity.

\section{B. Good practice example: The implementation of learner centered learning in a master degree course "Corporate Performance Management (CPM)"}

This example refers to a course project in the study program in strategic information management, master level, at Hasselt University and was used as an example of good practice from the Belgian partner in the WETEN project. In this course is shown how information systems can support the CPM in small and medium enterprises (SME). The assignment was 10 weeks in duration and included three parts. Part one dealt with theoretical concepts and methodology of CPM. Part two demonstrated and reinforced the CPM in small and medium enterprises. Part three included an information system - balanced scorecard (BSC) to support the selection process of CPM.

1) Part1: Theoretical concepts and methodology of CPM (Week 1 - 3)

Each learner was visiting the online university's library and searched for an article about a real world example, then he/she has written an essay, which contained a summary of the article's findings and learner's explanation of his/her thoughts and reactions based on his/her previous experience. This task was submitted at the end of Week 3.

\section{2) Part 2: CPM in SME (Week 4)}

Learners must read all their colleagues' postings and form questions based on their readings to be asked by a CPM expert.

Moreover, in this part the teacher was scheduling an asynchronous session on the discussion board with a CPM expert within a real employment organization to answer learners' questions.

Based on colleagues' postings and the discussion between learners and the CPM expert, each learner has written an essay about his/her thoughts, reaction, and/or viewpoints. 
3) Part 3: Information System supporting CPM (Week 5-10)

Learners were participating in a demonstration session about a real-world best practice CPM in a real company. The session was scheduled by the teacher. The teacher was also scheduling the asynchronous Q\&A session with an expert within the company to further explore and examine the CPM within the company. Based on the acquired experience, learners developed a set of quality criteria that could be used in the selection process of CPM using a balanced scorecard (BSC). In addition, in the last week, each learner was preparing a presentation summarizing his/her conclusions and what he/she has learnt from the real-world best practice, and shared it with his/her classmates using the online web2.0 tool "Slidesix".

The learning activities in this module started with exploration, in which learners searched for a real-world example. The activities were both individual and collaborative, with a high level of interaction among learners, expert consultants and the instructor.

Knowledge construction took place in individual contexts and through social negotiation, collaboration and experience. At all times the instructor guided, provided feedback to learners and assesses their learning (Facilitator's assessment).

\section{CASE WETEN: TRAINING THE UNIVERSITY TEACHERS}

\section{A. WETEN project: development of e-learning courses to train the teachers how to implement the learner centered concept}

To allow maximum flexibility in opportunities for retraining the academic staff from Higher Education Institutions from the neighborhood countries, an integrated approach was discussed and adopted. This approach included blended learning and preparation of the prerequisites for its implementation [18], [19]. The prerequisites referred to the elaboration of the syllabuses, the outline for the developed courses, guidelines for planning and designing of the digital content, choosing the open source technologies.

Five courses were elaborated and proposed for the continuous professional development of teaching staff. Courses were structured in accordance with the main subject areas to be studied and implemented by the teachers: 1) teaching/learning approaches in HE; 2) course design in $\mathrm{HE}$; 3) quality assurance; 4) ICT enhanced learning; 5) technologies and resources for e-learning.

By these courses we tried to promote:

- learning outcome based approach

- blended learning using ICT.

The proposed strategy was implemented in two phases.

Phase 1: process of studying the courses on level of knowing and understanding and getting personal insights into pedagogical and ICT innovations.

Learning process: teachers had studied the resources embedded in an open source learning management system, fulfilled the assignments and participate in the organized online activities. Some classroom sessions for teaching and discussions were organized.
Phase 2: process of applying the acquired knowledge in their own courses as teachers.

Learning process: the workshops held by EU staff were organized. In the workshops the teachers have applied the concepts from the proposed courses in a sample course. The redesigned course and the renewed course components were discussed during the workshops.

The main topics that needed to be discussed and explained were related to the learner centered approach and design of learner centered curriculum and courses [1]. The design model was extended to include the quality management aspects and the ICT aspects improving the learning process in both phases. Teamwork and collaborative learning, project based and problem based approaches were also discussed as having an important role in the higher level learning.

\section{B. Implementation of learner centered approach.}

The learner centered approach is a strategy that includes active learning, cooperative learning, and inductive learning. In active learning, learners solve problems, answer questions, formulate questions of their own, discuss, explain, debate, or brainstorm during teaching/learning sessions. In cooperative learning learners work in teams on problems and projects under conditions that assure both positive interdependence and individual accountability. In inductive teaching and learning learners are first presented with challenges (questions or problems) and learn the course material in the context of addressing these challenges. Inductive methods include inquiry-based learning, case-based instruction, problem-based learning, projectbased learning, discovery learning, and just-in-time teaching.

This strategy was implemented during training sessions and workshops organized for teaching staff within the project. In this way we tried to achieve the desired learning outcomes of the continuous professional development program: Two types of tasks were proposed to learners: 1) to construct some learning outcomes based on own experience and to design a course structure at learner choice with learning activities, assessment tasks and course topics; 2) to analyze the proposed examples of courses written in terms of objectives and poor defined learning outcomes and to redesign them in accordance with the student centered approach requirements.

The teachers were asked to create a context where the students are motivated to learn; this included providing content and resources and organizing constructivist learning activities. Teachers used methods from the cognitive and the social constructivism theories, and tried to implement individual learning methods such as discovery learning, and social interactive activities to develop peer collaboration. Debates were organized in the classrooms during face to face (f2f) sessions and workshops about the provision of means for learners to experience real world or meaningful practices.

\section{Learners'feedback}

The evaluation questionnaire was designed in order to collect the learners' feedback and to improve the courses content and delivery. The questions were grouped in several parts related to the course content, the learning environment and teaching methods, the learning effectiveness, the constructive course alignment. 
According to the teachers' opinions the courses were well organized, the learners had timely access to materials, they received feedback and had opportunities for collaboration. The learning outcomes were clear, the course learning activities and assignments were appropriate to achieve the learning outcomes. Learning resources were appreciated at very high level. They were useful for the development of the participants' own teaching materials and courses.

The participants' involvement in the course was different: some participated actively with oral and written contributions and made real progress; some were neutral (passive learners).

The developed courses, dealing with actual matters, were very useful for the enhancement of the quality of Higher Education. Almost all participants would recommend these courses to colleagues. Some teachers expressed the willing to make it compulsory for continuous teachers' development.

In general, blended learning within a LMS was quite new for the majority of teaching staff from the eastern universities. The participants were more acquainted with face to face sessions. Learning activities were supposed to be prepared as individual work (with some support from the project team). The results were presented in the classroom with participation of all learners. Learners were asked to comment on their own work and to give feedback to colleagues' work. The trainers' role was to stimulate collaboration, discussion and to offer feedback to all learners.

Strengths: Quality of learners' contributions, use of learners' experience in the field, collaborative learning, open learning environment. Constructivist approach was used implicitly. Tasks/assignments were related to the real teaching activities. LMS course materials can be updated easily any time.

Weaknesses: The implementation of student centered approach in practice was difficult. The learners' online collaboration was rather low. Planning of the $\mathrm{f} 2 \mathrm{f}$ sessions (small group sessions) was not easy, because finding a time period suitable to all teachers was rather difficult.

\section{CONCLUSIONS}

The evolution from teacher centered teaching to learner centered teaching is a new reality. It is linked with taking care for predefined set of competences.

Competences have to be identified and described for the curriculum based on discussions with other teachers and students.

The theory of constructivist learning has a strong focus on constructing new knowledge based on experiences with real practice, because a special focus is on the social constructivism theory.

A set of constructivist characteristics of learning, and a set of constructivist learning activities are listed. Some of them were applied in the learning process of the courses. Teachers developed competency directed and constructivism based learning processes.

It is a necessity to rethink the policies and the strategies for continuing professional development of HE teachers. Experiences in this field do exist, but are rare and do not constitute yet a well-organized system in Moldova. WETEN project represented an important opportunity to implement a continuous professional development model for HE teachers.

The emphasis of pedagogical competences is essential among the university teachers' qualifications.

The implementation of ICT into TLA is essential for effective learning results.

The student centered educational approach should be promoted and implemented into universities' practice.

\section{REFERENCES}

[1] J. Schreurs, A. Al-Hunedi, (2011): "Development of a learnercentred learning process for a course. case: The course Business Information Systems." In: Proceedings of Interactive Collaborative Learning (ICL). p. 256-263.

[2] D. Rutkauksiene, J. Schreurs, I. Huet, D. Gudoniene, (2010): "Train the teachers in student centred learning and teaching." In: Auer, Michael \& Schreurs, Jeanne (Ed.) Academic and corporate e-learning in a global context. p. 865-874.

[3] Levels of autonomy and responsibilities of teachers: http://eacea.ec.europa.eu/education/eurydice/documents/thematic reports/094en.pdf

[4] D. Rutkauskiene, D. Gudoniene, I. Huet, D. Casanova, J. Schreurs, (2011): "Pedagogic Traditions, skills and competences in higher education: Comparative analysis." In: Huet, I.; Rutkauskiene D.; Gudoniene D. (Ed.). Pedagogic Traditions, skills and competences in higher education: Comparative analysis, Kaunas University of Technology.

[5] D. Kennedy, A. Hyland, N. Ryan: "Writing and Using Learning Outcomes: a Practical guide.” http://sss.dcu.ie/afi/docs/bologna/ writing_and_using_learning_outcomes.pdf

[6] J. Biggs, C. Tang 2007. Teaching for Quality Learning at University, Open University Press/McGraw Hill. London, 3d edition.

[7] A. Koohang, L. Riley, T. Smith, J. Schreurs (2009): "E-Learning and Constructivism: From Theory to Application.”, In: Interdisciplinary Journal of e-learning and learning objects (IJELLO), 5. p. 91-109.

[8] C. Girvan, T. Savage 2010, "Identifying an appropriate pedagogy for virtual worlds: constructivism case study"; Center for Research in IT in education. School of computer science and statistics, Trinity College, University of Dublin, Ireland. Computers \& Education 55, 342-349. http://dx.doi.org/10.1016/j.compedu.2010.01.020

[9] J. Hannafin, S. M. Land, (1997), "The foundations and assumptions of technology-enhanced student-centred learning environments", Instructional Science 25, 167-202. http://dx.doi.org/ 10.1023/A:1002997414652

[10] S. Loynes, R. Rikers, H. Schmidt (2008), "Relationships between students' conceptions of constructivist learning and their regulation and processing strategies", Instructional Science, 36, 445-462. http://dx.doi.org/10.1007/s11251-008-9065-6

[11] S. Loyens, D. Gijbels (2008), "Understanding the effects of constructivist learning environments: introducing a multi-directional approach", Instructional Science, 36: 351-357 http://dx.doi.org/ 10.1007/s11251-008-9059-4

[12] A. Al-Huneidi, J. Schreurs (2011), "Constructivism based blended learning in higher education." In: Auer, E.M.; Hernandez Rizzardini, Rocael; Pester, A. (Ed.). Proceedings of the 4th International Conference on Interactive Computer-aided Blended Learning, International Association of Online Engineering.

[13] E. Murphy,(1997), "Constructivism: From philosophy to practice.” Retrieved Sept. 19, 2011: http://www.ucs.mun.ca/ emurphy/ stemnet/cle.htm

[14] L. Schuman :"Perspectives on instruction”, (1996), Retrieved July 05, 2010 from http://edweb.sdsu.edu/courses/edtec540/Perspec tives/Perspectives.html

[15] K. C. Powell and C. J. Kalina (2009), "Cognitive and social constructivism: developing tools for an effective classrooms". Education, Vol. 130, No. 3, pp. 241-250, Key: Citeulike: 7989421

[16] N. Sandhya, R. Baviskar, T. Hartle and T. Whitney, (2009), "Essential Criteria to Characterize Constructivist Teaching: Derived from a review of the literature and applied to five constructivistteaching method articles", International Journal of Science Edu- 
cation, Vol. 31, No. 4, pp. 541-550. http://dx.doi.org/10.1080/ 09500690701731121

[17] .J. C. Burguillo (2010), "Using game theory and competitionbased learning to stimulate student motivation and performance", Computers \& Education, Elsevier 55, 566-575. http://dx.doi.org/10.1016/j.compedu.2010.02.018

[18] H. Singh, (2003). "Building Effective Blended Learning Programs", Issue of Educational Technology, Volume 43, Number 6, Pages 51-54.

[19] R. Huang, D. Ma, and H. Zhang, "Towards a Design Theory of Blended Learning Curriculum.”, ICHL 2008, LNCS 5169, pp. 6678, 2008.

[20] EU: ECTS Users' Guide; Luxembourg: Office for Official Publications of the European Communities. 2009; ISBN:978-92-79-
09728-7, http://ec.europa.eu/education/lifelong-learning-policy/ doc/ects/guide_en.pdf, http://dx.doi.org/10.2766/88064

\section{AUTHORS}

J. Schreurs is Professor Emeritus in Business Informatics; Hasselt University, Faculty of Business Economic Sciences; Belgium. (jeanne.schreurs@uhasselt.be).

R. Dumbraveanu is with State Pedagogical University "Ion Creanga", Strada Ion Creangă 1, Chișinău 2069, Moldova (r.dumbraveanu@gmail.com).

Submitted, November 12, 2013. Published as resubmitted by the authors on June 13, 2014. 